Pacific Journal of Mathematics

A GENERALIZATION OF CARISTI'S THEOREM WITH
APPLICATIONS TO NONLINEAR MAPPING THEORY 


\title{
A GENERALIZATION OF CARISTI'S THEOREM WITH APPLICATIONS TO NONLINEAR MAPPING THEORY
}

\author{
David Downing AND W. A. KIRK
}

\begin{abstract}
Suppose $X$ and $Y$ are complete metric spaces, $g: X \rightarrow X$ an arbitrary mapping, and $f: X \rightarrow Y$ a closed mapping (thus, for $\left\{x_{n}\right\} \subset X$ the conditions $x_{n} \rightarrow x$ and $f\left(x_{n}\right) \rightarrow y$ imply $\left.f(x)=y\right)$. It is shown that if there exists a lower semicontinuous function $\varphi$ mapping $f(X)$ into the nonnegative real numbers and a constant $c>0$ such that for all $x$ in $X, \max \{d(x, g(x))$, $c d(f(x), \quad f(g(x))\} \leqq \varphi(f(x))-\varphi(f(g(x)))$, then $g$ has a fixed point in $X$. This theorem is then used to prove surjectivity theorems for nonlinear closed mappings $f: X \rightarrow Y$, where $X$ and $Y$ are Banach spaces.
\end{abstract}

1. Introduction. The following fact is well-known in the theory of linear operators;

(1.1) Let $X$ and $Y$ be Banach spaces with $D$ a dense subspace of $X$, and let $T: D \rightarrow Y$ be a closed linear mapping with dual $T^{\prime}$. Suppose the following two conditions hold:

(i ) $N\left(T^{\prime}\right)=\{0\}$.

(ii) For fixed $c>0$, dist $(x, N(T)) \leqq c\|T x\|, x \in D$. Then $T(D)=Y$.

Proof. Because $T$ is a closed mapping it routinely follows from (ii) that $T(D)$ is closed in $Y$ (e.g., [15, p. 72]), whence it follows from the Hahn-Banach theorem (cf. [17, p. 205]) that $\left(N\left(T^{\prime}\right)\right)^{\perp}=T(D)$ where $\left(N\left(T^{\prime}\right)\right)^{\perp}$ denotes the annihilator in $Y$ of the nullspace of $T^{\prime}$. By (i), $\left(N\left(T^{\prime}\right)\right)^{\perp}=Y$.

It is our objective in this paper to give a nonlinear generalization of the above along with more technical related results. The key to our approach is an application of a new generalized version of Caristi's fixed point theorem. While our method parallels that of Kirk and Caristi [12], these new results differ from those of [12] and the earlier 'normal solvability' results of others, e.g., Altman [1], Browder [3-6], Pohozhayev [13, 14], and Zabreiko-Krasnoselskii [18], in that by using the improved fixed point theorem we are able to replace the usual closed range assumption with the assumption that the mapping be closed (in conjunction with a condition which in the linear case reduces to (ii)). Before doing this, however, we state and prove our fixed point theorem. 
2. The fixed point theorem. The following theorem reduces to the theorem of Caristi $[7,8]$ in the case that $X=Y, f$ is the identity mapping, and $c=1$. (We should remark that Caristi's theorem is essentially equivalent to a theorem stated earlier by Ekeland [9]. A simple proof along the general lines below is implicit in Brøndsted [2]. A similar proof is given by Kasahara in [10], and in [16] Wong gives a simplified version of Caristi's original transfinite induction argument.)

THEOREM 2.1. Let $X$ and $Y$ be complete metric spaces and $g: X \rightarrow X$ an arbitrary mapping. Suppose there exists a closed mapping $f: X \rightarrow Y$, a lower semicontinuous mapping $\varphi: f(X) \rightarrow R^{+}$, and a constant $c>0$ such that for each $x \in X$,

$$
\left\{\begin{array}{l}
d(x, g(x)) \leqq \varphi(f(x))-\varphi(f(g(x))), \quad \text { and } \\
c d(f(x), f(g(x))) \leqq \varphi(f(x))-\varphi(f(g(x))) .
\end{array}\right.
$$

Then there exists $\bar{x} \in X$ such that $g(\bar{x})=\bar{x}$.

Proof. We introduce a partial order $\leqq$ in $X$ as follows. For $x, y \in X$ define $x \leqq y$ provided

$$
\left\{\begin{array}{l}
d(x, y) \leqq \varphi(f(x))-\varphi(f(y)), \text { and } \\
c d(f(x), f(y)) \leqq \varphi(f(x))-\varphi(f(y)) .
\end{array}\right.
$$

Let $\left\{x_{\alpha}\right\}_{\alpha \in I}$ be any chain in $X$, i.e., suppose $(I, \leqq)$ is a totally ordered set with $x_{\alpha} \leqq x_{\beta}$ iff $\alpha \leqq \beta$. Then $\left\{\varphi\left(f\left(x_{\alpha}\right)\right)\right\}_{\alpha \in I}$ is a decreasing net in $R^{+}$so there exists $r \geqq 0$ such that $\varphi\left(f\left(x_{\alpha}\right)\right) \downarrow r$. Let $\varepsilon>0$. Then there exists $\alpha_{0} \in I$ such that $\alpha \geqq \alpha_{0}$ implies

$$
r \leqq \varphi\left(f\left(x_{\alpha}\right)\right) \leqq r+\varepsilon
$$

and so for $\beta \geqq \alpha$,

$$
\begin{aligned}
& d\left(x_{\alpha}, x_{\beta}\right) \leqq \varphi\left(f\left(x_{\alpha}\right)\right)-\varphi\left(f\left(x_{\beta}\right)\right) \leqq \varepsilon, \quad \text { and } \\
& \quad c d\left(f\left(x_{\alpha}\right), f\left(x_{\beta}\right)\right) \leqq \varphi\left(f\left(x_{\alpha}\right)\right)-\varphi\left(f\left(x_{\beta}\right)\right) \leqq \varepsilon .
\end{aligned}
$$

Thus $\left\{f\left(x_{\alpha}\right)\right\}$ is a Cauchy net in $Y$ while $\left\{x_{\alpha}\right\}$ is a Cauchy net in $X$. By completeness there exist $\bar{y} \in Y$ and $\bar{x} \in X$ such that $f\left(x_{\alpha}\right) \rightarrow \bar{y}$ and $x_{\alpha} \rightarrow \bar{x}$. Since $f$ is a closed mapping, $f(\bar{x})=\bar{y}$ and lower-semicontinuity of $\varphi$ yields $\varphi(f(\bar{x})) \leqq r$. Moreover, if $\alpha, \beta \in I$ with $\alpha \leqq \beta$, then

$$
\begin{gathered}
d\left(x_{\alpha}, x_{\beta}\right) \leqq \varphi\left(f\left(x_{\alpha}\right)\right)-\varphi\left(f\left(x_{\beta}\right)\right) \leqq \varphi\left(f\left(x_{\alpha}\right)\right)-r ; \\
c d\left(f\left(x_{\alpha}\right), f\left(x_{\beta}\right)\right) \leqq \varphi\left(f\left(x_{\alpha}\right)\right)-r .
\end{gathered}
$$

Taking limits with respect to $\beta$ yields 


$$
\begin{gathered}
d\left(x_{\alpha}, \bar{x}\right) \leqq \varphi\left(f\left(x_{\alpha}\right)\right)-r \leqq \varphi\left(f\left(x_{\alpha}\right)\right)-\varphi(f(\bar{x})) ; \\
c d\left(f\left(x_{\alpha}\right), f(\bar{x})\right) \leqq \varphi\left(f\left(x_{\alpha}\right)\right)-\varphi(f(\bar{x})) .
\end{gathered}
$$

This proves that $x_{\alpha} \leqq \bar{x}, \alpha \in I$.

Having thus shown that every totally ordered set in $(X, \leqq)$ has an upper bound we apply Zorn's lemma to obtain maximal element $x \in X$. By $\left({ }^{*}\right), x \leqq g(x)$; hence $x=g(x)$.

3. Applications. If $X$ and $Y$ are topological vector spaces and $f: X \rightarrow Y$, then $f$ is said to be Gâteaux differentiable at $x \in X$ if there exists a (possibly unbounded) linear operator $L: X \rightarrow Y$ such that for each $w \in X$,

$$
t^{-1}(f(x+t w)-f(x)) \longrightarrow L w \text { as } t \longrightarrow 0^{+} .
$$

The operator $L=d f_{x}$ is called the Gâteaux derivative of $f$ at $x$ and we use $d f_{x}^{\prime}$ to denote the dual of $d f_{x}$ in the usual sense (e.g., $[17$, p. 194]).

We now state a theorem which is an immediate generalization of the theorem of the introduction. Notationally, we let $B_{\delta}(\cdot)$ denote the closed ball centered at $(\cdot)$ with radius $\delta$. Also, $N\left(d f_{x}^{\prime}\right)$ denotes the nullspace of $d f_{x}^{\prime}$ in $Y^{*}$, the space of all continuous linear functionals on $Y$, and $\left(N\left(d f_{x}^{\prime}\right)\right)^{\perp}$ denotes its annihilator in $Y$.

THEOREM 3.1. Let $X$ and $Y$ be Banach spaces and $f: X \rightarrow Y$ $\alpha$ (nonlinear) closed mapping which is Gâteaux differentiable at each $x \in X$ with derivative $d f_{x}$. Let $d f_{x}^{\prime}$ denote the dual of $d f_{x}$, and suppose for each $x \in X$ and fixed $c>0$ :

(i ) $\quad N\left(d f_{x}^{\prime}\right)=\{0\}$.

(ii)' There exists $\delta=\delta(x)>0$ such that if $y \in B_{\delta}(f(x)) \cap f(X)$, then for some $v \in f^{-1}(y)$,

$$
\|x-v\| \leqq c\|f(x)-y\| .
$$

Then $f(X)=Y$.

It is obvious that (i) reduces to (i) in the linear case and it is a routine matter to show that (ii)' similarly reduces to (ii). In contrast with the linear case, however, we do not show directly that (ii)' implies closedness of the range of $f$. Instead we derive Theorem 3.1 from the following more general result which follows quite easily from Theorem 2.1.

THEOREM 3.2. Suppose $X$ is a complete metric space, $Y$ a Banach space, and $f: X \rightarrow Y$ a closed mapping. Suppose for $y_{0} \in Y$ there exist constants $c>0, p<1$ such that: 
(a) Corresponding to each $x \in X$ there exists $\delta=\delta(x)>0$ such that if $y \in B_{\delta}(f(x)) \cap f(X)$, then

$$
d(x, v) \leqq c\|f(x)-y\|
$$

for some $v \in f^{-1}(y)$.

(b) For each $y \in f(X)$ there exists a sequence $\left\{y_{j}\right\}$ in $f(X)$ with $y_{j} \neq y$ for each $j$ such that $y_{j} \rightarrow y$ and a sequence $\left\{\xi_{j}\right\}$ of nonnegative real numbers such that for each $j$

$$
\left\|\xi_{j}\left(y_{j}-y\right)-\left(y_{0}-y\right)\right\| \leqq p\left\|y_{0}-y\right\| \text {. }
$$

Then $y_{0} \in f(X)$.

The following geometric lemma, implicit in [12], will facilitate the proof of Theorem 3.2.

Lemma. Let $Y$ be a normed linear space with $a, b, c \in Y$. Suppose for $\xi \geqq 1$ and $p<1$,

$$
\|\xi(a-b)-(c-b)\| \leqq p\|c-b\| \text {. }
$$

Then

$$
\|a-b\| \leqq(1+p)(1-p)^{-1}[\|b-c\|-\|a-c\|] .
$$

Proof.

$$
\begin{aligned}
& \|\xi(a-c)\|-\|(1-\xi)(b-c)\| \\
& \quad \leqq\|\xi(a-c)+(1-\xi)(b-c)\| \\
& \quad=\|\xi(a-b)-(c-b)\| \\
& \quad \leqq p\|b-c\| .
\end{aligned}
$$

Thus $\|\xi(a-c)\| \leqq(\xi-1+p)\|b-c\|$, i.e.,

$$
\|a-c\| \leqq\left[1-\xi^{-1}(1-p)\right]\|b-c\|
$$

from which (using $\left(^{*}\right)$ and the triangle inequality)

$$
\begin{aligned}
\|b-c\|-\|a-c\| & \geqq\left\{1-\left[1-\xi^{-1}(1-p)\right]\right\}\|b-c\| \\
& =\xi^{-1}(1-p)\|b-c\| \\
& \geqq \xi^{-1}(1-p) \xi(1+p)^{-1}\|a-b\| \\
& =(1-p)(1+p)^{-1}\|a-b\| .
\end{aligned}
$$

Proof of Theorem 3.2. Suppose $y_{0} \notin f(X)$. Let $x \in X$ and $y=f(x)$, and let $\left\{y_{j}\right\}$ be the sequence defined by (b). Since $y_{j} \rightarrow y$, $j$ may be chosen so large that $\left\|y_{j}-y\right\| \leqq \delta(x)$. We also assume $\xi_{j} \geqq 1$. (Note that since $y_{0} \neq y$, (b) implies $\xi_{j} \rightarrow+\infty$.) With $j$ thus fixed we apply the lemma to the inequality in (b) and obtain 
(1)

$$
0<\left\|y-y_{j}\right\| \leqq(1+p)(1-p)^{-1}\left[\left\|y-y_{0}\right\|-\left\|y_{j}-y_{0}\right\|\right]
$$

By (a) there exists $v \in f^{-1}\left(y_{j}\right)$ such that

$$
d(x, v) \leqq c\left\|y-y_{j}\right\| \text {. }
$$

Define $g: X \rightarrow X$ by taking $g(x)=v$ with $v$ obtained as above, and define $\varphi: f(X) \rightarrow R^{+}$by

$$
\varphi(f(x))=c(1+p)(1-p)^{-1}\left\|f(x)-y_{0}\right\| .
$$

Then clearly $\varphi$ is continuous on $f(X)$ and together (1) and (2) yield

$$
\left\{\begin{array}{l}
d(x, g(x)) \leqq \varphi(f(x))-\varphi(f(g(x))), \quad \text { and } \\
c\|f(x)-f(g(x))\| \leqq \varphi(f(x))-\varphi(f(g(x))) .
\end{array}\right.
$$

By Theorem 2.1 there exists $\bar{x} \in X$ such that $g(\bar{x})=\bar{x}$, contradicting (1).

In order to derive Theorem 3.1 from Theorem 3.2 we need an elementary fact from linear algebra. Let $X$ and $Y$ be locally convex topological vector spaces and suppose $L: X \rightarrow Y$ is a linear operator. The dual $L^{\prime}$ of $L$ (cf. [17, p. 194]) is defined on a subset $D$ of $Y^{*}$ by the relation

$$
\left\langle x, L^{\prime} y^{\prime}\right\rangle=\left\langle L x, y^{\prime}\right\rangle, \quad y^{\prime} \in D, \quad x \in X
$$

where $X^{*}$ and $Y^{*}$ denote respectively the spaces of continuous linear functionals on $X$ and $Y$ and where by assumption $\left\langle\cdot, L^{\prime} y^{\prime}\right\rangle \epsilon$ $X^{*}$. If $\left(N\left(L^{\prime}\right)\right)^{\perp}$ denotes the annihilator of $N\left(L^{\prime}\right)$ in $Y$ it routinely follows from the Hahn-Banach theorem that $\left.\left(N\left(L^{\prime}\right)\right)^{\perp} \subset \overline{L(X}\right)$. (For, suppose there exists $y_{0} \in\left(N\left(L^{\prime}\right)\right)^{\perp}$ with $y_{0} \notin \overline{L(X)}$. Then there exists $y^{\prime} \in Y^{*}$ such that $\left\langle y_{0}, y^{\prime}\right\rangle \neq 0$ while $\left\langle z, y^{\prime}\right\rangle=0$ for all $z \in \overline{L(X)}$; hence $\left\langle L u, y^{\prime}\right\rangle=\left\langle u, L^{\prime} y^{\prime}\right\rangle=0$ for all $u \in X$ yielding $L^{\prime} y^{\prime}=0$, i.e., $y^{\prime} \in N\left(L^{\prime}\right)$. Since $y_{0} \in\left(N\left(L^{\prime}\right)\right)^{\perp}$ implies $\left\langle y_{0}, y^{\prime}\right\rangle=0$, we have a contradiction.)

We now follow an approach of Browder [4,6]. With $X$ as above and $Y$ a Banach space the asymptotic direction set of the mapping $f: X \rightarrow Y$ in the direction $x \in X$ is the set

$$
D_{x}(f)=\bigcap_{\varepsilon>0} c 1(\{y \in Y \mid y=\xi(f(u)-f(x)), \xi \geqq 0, u \in X,\|f(u)-f(v)\|<\varepsilon\}) .
$$

The following is a minor variant of Proposition 1 of $[4,6]$. We include the proof to show that continuity of $d f_{x}$ is not essential.

Proposition 3.1. Let $X$ be a locally convex topological vector space, $Y$ a Banach space, and suppose $f$ is a mapping of $X$ into $Y$ which is Gâteaux differentiable at $x \in X$ with derivative $d f_{x}$. If 
$N\left(d f_{x}^{\prime}\right)$ denotes the nullspace in $Y^{\prime}$ of the dual of $d f_{x}$ and if $\left(N\left(d f_{x}^{\prime}\right)\right)^{\perp}$ denotes its annihilator in $Y$, then

$$
\left(N\left(d f_{x}^{\prime}\right)\right)^{\perp}=\overline{d f_{x}(X)} \subset D_{x}(f) .
$$

Proof. The equality is immediate from observations above. To see that $\overline{d f_{x}(X)} \subset D_{x}(f)$ we follow [6]: Let $\varepsilon>0$ and $y \in d f_{x}(X)$. Then $y=d f_{x}(w)$ for some $w \in X$ and by differentiability

$$
t^{-1}(f(x+t w)-f(x)) \longrightarrow y \text { as } t \longrightarrow 0^{+} \text {. }
$$

Letting $x_{t}=x+t w$ we have for $t>0$ sufficiently small, $\| f\left(x_{t}\right)$ $f(x) \|<\varepsilon$. It follows from this and $(\#)$ that

$$
y \in \operatorname{cl}\{\xi(f(u)-f(x)) \mid \xi \geqq 0, u \in X,\|f(u)-f(x)\|<\varepsilon\} ;
$$

i.e., $y \in D_{x}(f)$. Since $D_{x}(f)$ is closed, $\overline{d f_{x}(X)} \subset D_{x}(f)$.

Proof of Theorem 3.1. Let $y_{0} \in Y, p \in(0,1)$. It suffices to establish (b) of Theorem 3.2. Suppose $y=f(x) \in f(X), y \neq y_{0}$. Since $N\left(d f_{x}^{\prime}\right)=\{0\},\left(N\left(d f_{x}^{\prime}\right)\right)^{\perp}=Y$ and by Proposition 3.1

$$
y_{0}-f(x) \in D_{x}(f) \text {. }
$$

Choose $\varepsilon_{j}>0$ with $\varepsilon_{j} \rightarrow 0$. For each $j$ there exists $z_{j} \in X$ and $\xi_{j} \geqq 0$ such that

$$
\left\|\xi_{j}\left(f\left(z_{j}\right)-f(x)\right)-\left(y_{0}-f(x)\right)\right\| \leqq p\left\|y_{0}-f(x)\right\|
$$

and

$$
\left\|f\left(z_{j}\right)-f(x)\right\|<\varepsilon_{j} .
$$

Letting $y_{j}=f\left(z_{j}\right)$, since $p<1$ (3) implies $y_{j} \neq y$ for all $j$. By (4) $y_{j} \rightarrow y$ as $j \rightarrow \infty$ and rewriting (3) we have

$$
\left\|\xi_{j}\left(y_{j}-y\right)-\left(y_{0}-y\right)\right\| \leqq p\left\|y_{0}-y\right\| \text {. }
$$

This completes the proof.

Finally we note that if int $\overline{f(X)} \neq \varnothing$, it is not necessary in Theorem 3.1 to assume $f$ is differentiable at each $x \in X$.

THEOREM 3.3. Let $X$ and $Y$ be Banach spaces and $f: X \rightarrow Y$ a closed mapping. Let $N=\{x \in X \mid f(x) \in \operatorname{int} \overline{f(X)}\}$ and suppose for $x \in X \backslash N, f$ is Gâteaux differentiable with derivative $d f_{x}$ where $N\left(d f_{x}^{\prime}\right)=\{0\}$. Suppose also that there exists $c>0$ such that condition (ii)' of Theorem 3.1 holds for all $x \in X$. Then $f(X)=Y$. 
Proof. Let $y_{0} \in Y$ and suppose $y_{0} \notin f(X)$. Fix $p \in(0,1)$ and let $x \in X$. If $x \in X \backslash N$, then $\left(N\left(d f_{x}^{\prime}\right)\right)^{\perp}=Y$ and by Proposition 3.1, $y_{0}-$ $f(x) \in D_{x}(f)$. But also if $x \in N$, i.e., if $f(x) \in \operatorname{int} \overline{f(X)}$, then for $\varepsilon>0$ chosen so that $B_{\varepsilon}(f(x)) \subset \overline{f(X)}$ it is possible to select $w \in \operatorname{seg}\left[f(x), y_{0}\right]$ so that $w \neq y_{0}$ and $0<\|f(x)-w\|<\varepsilon$, and because $w \in \overline{f(X)}$ there exists $\left\{w_{j}\right\} \subset f(X)$ such that $w_{j} \rightarrow w$. Since $y_{0}-f(x)=\xi(w-f(x))$ for $\xi>0$ it thus follows that $\xi\left(w_{j}-f(x)\right) \rightarrow y_{0}-f(x)$ with $\| w_{j}-$ $f(x) \|<\varepsilon$ for $j$ sufficiently large proving $y_{0}-f(x) \in D_{x}(f)$. Since $y_{0}-f(x) \in D_{x}(f)$, the proof now follows the proof of Theorem 3.1.

We remark that as a consequence of the above theorem, if $f: X \rightarrow Y$ is a closed mapping with range dense in $Y$, then (ii)' of Theorem 3.1 implies $f(X)=Y$.

\section{REFERENCES}

1. M. Altman, Contractor directions, directional contractors and directional contractions for solving equations, Pacific J. Math., 62(1976), 1-18.

2. A. Brondsted, On a lemma of Bishop and Phelps, Pacific J. Math., 55 (1974), 335-341.

3. F.E. Browder, Normal solvability and the Fredholm alternative for mappings in infinite dimensional manifolds, J. Functional Analysis, 8(1971), 250-274.

4. - Normal solvability for nonlinear mappings in Banach spaces, Bull. Amer. Math. Soc., 77(1971), 73-77.

5 . - Normal solvability and $\phi$-accretive mappings of Banach spaces, Bull. Amer. Math. Soc., 78(1972), 186-192.

6. - Normal solvability for nonlinear mappings and the geometry of Banach spaces, Proc. CIME Conf. (Varenna, (1970)), Problems in Nonlinear Analysis, Edizioni Cremonese, Rome (1971), 39-66.

7. J. Caristi, Fixed point theorems for mappings satisfying inwardness conditions, Trans. Amer. Math. Soc., 215 (1976), 241-251.

8) J. Caristi and W. A. Kirk, Geometric fixed point theory and inwardness conditions, Proc. Conf. on Geometry of Metric and Linear Spaces (Michigan, (1974), Lecture Notes in Mathematics v. 490, Springer-Verlag, (1975), 75-83.

9. I. Ekeland, Sur les problemes variationnels, Comptes Rendus Acad. Sci. Paris, 275 (1972), 1057-1059.

10. S. Kasahara, On fixed points in partially ordered sets and Kirk-Caristi theorem, Math. Seminar Notes XXXV, Kobe University, 2(1975).

11. W. A. Kirk, Caristi's fixed point theorem and the theory of normal solvability, Seminar on Fixed Point Theory and its Applications, Dalhousie University, 1975.

12. W. A. Kirk and J. Caristi, Mapping theorems in metric and Banach spaces, Bull. de l'Academie Polonaise des Sciences, 23 (1975), 891-894.

13. S. I. Pohozhayev, On the normal solvability of nonlinear operators, Dokl. Akad. Nauk SSSR, 184 (1969), 40-43.

14. - On nonlinear operators having weakly closed images and quasilinear elliptic equations, Mat. Sb., 78 (1969), 237-259.

15. M. Schechter, Principles of Functional Analysis, Academic Press, New York, (1971).

16. C. S. Wong, On a fixed point theorem of contractive type, Proc. Amer. Math.

Soc., 57(1976), 283-284.

17. K. Yosida, Functional Analysis, Springer-Verlag, Berlin, (1965). 
18. P. P. Zabreiko and M. A. Krasnoselskii, Solvability of nonlinear operator equations, Functional Anal. i Prilozen 3(1969), 80-84; English trnslation: Functional Anal. Appl. 5(1971), 206-208.

Received July 16, 1976, Research supported in part by a National Science Foundation grant.

UNIVERSITY OF IOWA

IowA City, IA 52242 


\section{PACIFIC JOURNAL OF MATHEMATICS}

\section{EDITORS}

RICHARD ARENS (Managing Editor)

University of California

Los Angeles, CA 90024

R. A. BEAUMONT

University of Washington

Seattle, WA 98105

C. C. Moore

University of California

Berkeley, CA 94720

\section{J. DugundJI}

Department of Mathematics

University of Southern California

Los Angeles, CA 90007

R. Finn and J. Milgram

Stanford University

Stanford, CA 94305

\section{ASSOCIATE EDITORS}

\section{E. F. BECKENBACH}

B. H. NEUMANN

F. WoLF

K. YOSHIDA

\section{SUPPORTING INSTITUTIONS}

\author{
UNIVERSITY OF BRITISH COLUMBIA \\ CALIFORNIA INSTITUTE OF TECHNOLOGY \\ UNIVERSITY OF CALIFORNIA \\ MONTANA STATE UNIVERSITY \\ UNIVERSITY OF NEVADA \\ NEW MEXICO STATE UNIVERSITY \\ OREGON STATE UNIVERSITY \\ UNIVERSITY OF OREGON \\ OSAKA UNIVERSITY
}

\author{
UNIVERSITY OF SOUTHERN CALIFORNIA \\ STANFORD UNIVERSITY \\ UNIVERSITY OF HAWAII \\ UNIVERSITY OF TOKYO \\ UNIVERSITY OF UTAH \\ WASHINGTON STATE UNIVERSITY \\ UNIVERSITY OF WASHINGTON \\ AMERICAN MATHEMATICAL SOCIETY
}

The Supporting Institutions listed above contribute to the cost of publication of this Journal, but they are not owners or publishers and have no responsibility for its content or policies.

Mathematical papers intended for publication in the Pacific Jaurnal of Mathematics should be in typed form or offset-reproduced, (not dittoed), double spaced with large margins. Please do not use built up fractions in the text of your manuscript. You may however, use them in the displayed equations. Underline Greek letters in red, German in green, and script in blue. The first paragraph or two must be capable of being used separately as a synopsis of the entire paper. Items of the bibliography should not be cited there unless absolutely necessary, in which case they must be identified by author and Journal, rather than by item number. Manuscripts, in triplicate, may be sent to any one of the editors. Please classify according to the scheme of Math. Reviews, Index to Vol. 39. All other communications should be addressed to the managing editor, or Elaine Barth, University of California, Los Angeles, California, 90024.

The Pacific Journal of Mathematics expects the author's institution to pay page charges, and reserves the right to delay publication for nonpayment of charges in case of financial emergency

100 reprints are provided free for each article, only if page charges have been substantially paid. Additional copies may be obtained at cost in multiples of 50 .

The Pacific Journal of Mathematics is issued monthly as of January 1966. Regular subscription rate: $\$ 7200$ a year (6 Vols., 12 issues). Special rate: $\$ 36.00$ a year to individual members of supporting institutions.

Subscriptions, orders for back numbers, and changes of address should be sent to Pacific Journal of Mathematics, 103 Highland Boulevard, Berkeley, California, 94708.

PUBLISHED BY PACIFIC JOURNAL OF MATHEMATICS, A NON-PROFIT CORPORATION

Printed at Kokusai Bunken Insatsusha (International Academic Printing Co., Ltd.). 8-8, 3-chome, Takadanobaba, Shinjuku-ku, Tokyo 160, Japan.

Copyrit (C) 1975 by Pacific Journal of Mathematics Manufactured and first issued in Japan 


\section{Pacific Journal of Mathematics \\ Vol. 69, No. $2 \quad$ June, 1977}

Carol Alf and Thomas Alfonso O'Connor, Unimodality of the Lévy spectral

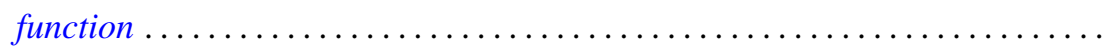

S. J. Bernau and Howard E. Lacey, Bicontractive projections and reordering of

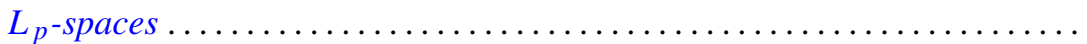

Andrew J. Berner, Products of compact spaces with bi-k and related spaces..... 303

Stephen Richard Bernfeld, The extendability and uniqueness of solutions of ordinary differential equations ...............................

Marilyn Breen, Decompositions for nonclosed planar m-convex sets ..........

Robert F. Brown, Cohomology of homomorphisms of Lie algebras and Lie

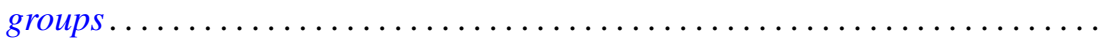

Jack Douglas Bryant and Thomas Francis McCabe, A note on Edelstein's iterative test and spaces of continuous functions ....................

Victor P. Camillo, Modules whose quotients have finite Goldie dimension ....... 333

David Downing and William A. Kirk, A generalization of Caristi's theorem with

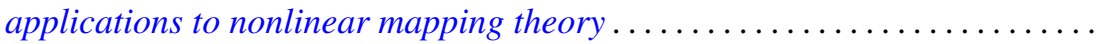

Daniel Reuven Farkas and Robert L. Snider, Noetherian fixed rings ...........

Alessandro Figà-Talamanca, Positive definite functions which vanish at

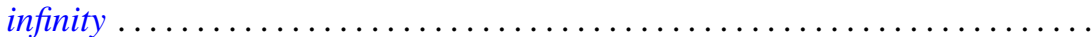

Josip Globevnik, The range of analytic extensions .................. 365

André Goldman, Mesures cylindriques, mesures vectorielles et questions de

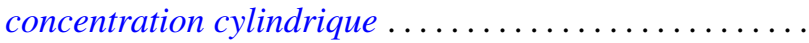

Richard Grassl, Multisectioned partitions of integers..........

Haruo Kitahara and Shinsuke Yorozu, A formula for the normal part of the

Laplace-Beltrami operator on the foliated manifold .... .

Marvin J. Kohn, Summability $R_{r}$ for double series .........

Charles Philip Lanski, Lie ideals and derivations in rings with involution ..

Solomon Leader, A topological characterization of Banach contractions . .

Daniel Francis Xavier O’Reilly, Cobordism classes of fiber bundles . .

James William Pendergrass, The Schur subgroup of the Brauer group . .

Howard Lewis Penn, Inner-outer factorization of functions whose Fourier series

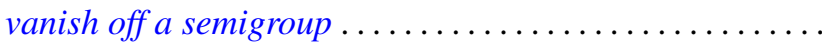

501

William T. Reid, Some results on the Floquet theory for disconjugate definite

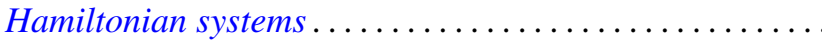

Caroll Vernon Riecke, Complementation in the lattice of convergence

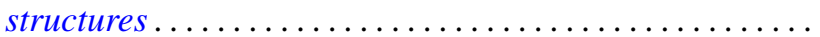

Louis Halle Rowen, Classes of rings torsion-free over their centers ......... 527

Manda Butchi Suryanarayana, A Sobolev space and a Darboux problem ....... 535

Charles Thomas Tucker, II, Riesz homomorphisms and positive linear maps.... 551

William W. Williams, Semigroups with identity on Peano continua ........... 557

Yukinobu Yajima, On spaces which have a closure-preserving cover by finite 